\title{
The taxonomy of higher vascular plants, lichens and fungi in the city of Abakan (Republic of Khakassia)
}

\author{
Elena Lagunova*, and Olga Larina \\ Katanov Khakassia State University, 655017 Abakan, Russia
}

\begin{abstract}
The flora of vascular plants in the city of Abakan (Republic of Khakassia, Russia) is represented by 459 taxa belonging to 69 families and 325 genera. Angiosperms are predominant in the flora of higher vascular plants and are represented by 451 species ( $98.3 \%$ of the entire city flora), including monocotyledons (104 species, 22.7\%) and dicotyledons (347 species, 75.6\%). According to these indicators, the flora of this city belongs to temperate floras of the Holarctic. The presence of 24 singlespecies families in the Abakan flora is related to the observed poor state of environment-forming factors, which prevents the adaptation of species under the new transformed conditions of the urbanized environment. Lichens in Abakan are represented by 33 species affiliated with 18 genera and 8 families. There are 125 mushroom species belonging to 75 genera, 34 families, 6 orders, and a single class, Agaricomycetes.
\end{abstract}

\begin{abstract}
Abakan is the capital of the Republic of Khakassia (Russian Federation). This city is located in the central part of the Minusinsk depression, at an altitude of $250 \mathrm{~m}$ above sea level. The city' vegetation is formed under the influence of the natural steppes that surround it. The hydrology of Abakan has a strong impact on its vegetation and is in turn affected by nearby rivers such as the Yenisei, Abakan, and Tasheba and drainage channels, which determine the emergence of meadows in the city and its environs.

As a result of the influence of anthropogenic factors, natural conditions of the environment are transformed, with the first change occurring in plant species and their set and ratios. In urbanized ecosystems, the most widespread anthropogenic factors include the following: planting of trees and shrubs and allocation of land to such activities as construction and recreation. Ultimately, the urban territory becomes an environment suitable for the adaptation of alien species and a place for their subsequent spreading settlement in natural plant communities.

In relation to the synanthropization and degradation of vegetation in the city, the urban vegetation in question can be categorized into cultivated (which includes garden-park complexes) and natural (exemplified by steppes, meadows, and poplar forests in the floodplain of the Abakan River) [1]. Natural vegetation, which has persisted in fragments within this city, is barely present in the area occupied by apartment and office buildings.
\end{abstract}

* Corresponding author: lglagunova@mail.ru 
Natural plant communities are much more common in the vicinity of the city being analyzed, where they occupy substantial areas.

In this study, the collection of higher vascular plants was carried out by the route method within the administrative boundaries of the city; besides, model plots were designated on the city territory by the method of N. G. Ilminskich [2]; these plots covered all types of plantings in the city: gardens, parks, squares, greenery along streets, and territories adjoining houses and buildings as well as valleys of the Abakan and Tasheba rivers, drainage canals, steppe areas, and railroad slopes. In accordance with the concepts proposed by N. N.Tzvelev [3], the study covered the cultivated introduced species growing in the city. The collection of lichens in the summer and autumn months was performed by the method of A. N. Oxner [4].

Abakan flora consists of 459 species of higher vascular plants belonging to 69 families and 325 genera. The bulk of the flora is composed of angiosperms: 67 families $(97.1 \%$ of the entire city flora), 321 genera $(98.8 \%)$, and 451 species $(98.3 \%)$. Vascular spore plants include 1 family (Equisetaceae, 1.4\%), 1 genus (Equisetum, 0.3\%), and 4 species $(0.9 \%)$ : Equisetum arvense L., E. fluviatile L., E. hyemale L., and E. pratense L.; the found gymnosperms include 1 family (Pinaceae, 1.4\%), 3 genera (Larix, Picea, and Pinus; 0.9\%), and 4 species (0.9\%): Larix sibirica Ledeb., Picea obovata Ledeb., Picea pungens Engelm, and Pinus sylvestris L.

One of the key characteristics of flora taxonomy is the family profile. Ten leading families correspond to $63.8 \%$ of all the plant species in the Abakan flora. The largest families (Asteraceae, Poaceae, Rosaceae, Fabaceae, and Cyperaceae) are in the lead. Members of these families constitute the background vegetation of the city. The Asteraceae family, which features 57 species here (12.4\%), is also the most widespread family in the flora of Khakassia [5], and its members are found almost everywhere, both in natural habitats and in urbanized ones (Artemisia vulgaris L., Achillea millefolium L., Aster alpinus L., Tanacetum vulgare L., Taraxacum officinale L., and others).

The Poaceae family takes the second place and is represented by 54 species $(11.8 \%)$. Members of this family are widespread in steppes, in meadows, on lawns, and along roads. Typical representatives are Agropyron cristatum (L.) Gaertn., Echinochloa crus-galli (L.) P. Beauv., Koeleria cristata (Ledeb.) Schult., Phleum phleoides (L.) H. Karst., Poa annua L., and others.

The Rosaceae family takes the third place and includes 44 species here (9.6\%), 24 of which are adventive species, such as Amygdalus nana L., Cotoneaster lucidus Schltdl., Malus baccata (L.) Borkh., Sorbaria sorbifolia (L.) A. Braun, Crataegus dahurica Koehne ex C.K. Schneid., and Pyrus ussuriensis Maxim. These species are widely used in the landscaping of this city and are cultivated in parks and gardens.

Members of the Fabaceae family here comprise 32 species $(7.0 \%)$. The species of this family are characterized by strong adaptation to urbanized conditions; for example, Trifolium pratense L., T. repens L., Medicago sativa L., Onobrychis arenaria (Kit.) DC., Vicia cracca L. and others are widespread within city limits in degraded meadows, along roads, and in parks and squares.

The hygrophilous family Cyperaceae [e.g., Carex duriuscula C.A. Mey, C. acuta L., C. dichroa (Freyn) V.I. Krecz., Eleocharis palustris (L.) Roem. \& Schult., and Scirpus radicans Schkuhr] is in the fifth place and includes 23 species here, which is $5.0 \%$ of the total number of plant species in Abakan. The role of this family is considerably lower in the city flora than in natural flora [5]. This can be explained by the observation that sedge species in the city are deprived of their respective habitats and, in the opinion of M. A. Berezutsky [6], it is this family that can be used as a metric of anthropogenic transformation of flora. 
The presence of the Brassicaceae family is substantial here, which includes 22 species (4.8\%). The abundance of this family's species is mainly determined by the anthropogenic impact because the study area is located within city boundaries. A high proportion of this family in flora is a diagnostic feature of the flora of urbanized territories [7]. The species that spread because of human activities are Capsella bursa-pastoris (L.) Medikus, Berteroa incana (L.) DC., Descurainia Sophia (L.) Webb ex Prantl, Lepidium ruderale L., and others.

The Ranunculaceae family also includes 22 species (4.8\%). Mostly, these are species from the genus Ranunculus that prefer conditions with sufficient moistening. Species Ranunculus propinquus C.A. Mey., R. acris L., Thalictrum simplex L., Aconitum volubile Pall. ex Koelle, and others occur in floodplain meadows and occasionally in parks.

The Lamiaceae family is represented by 15 species (3.3\%). This family here mainly includes perennial herbaceous plants growing on moist soils [Glechoma hederacea L., Lamium album L., Phlomis tuberosa (L.) Moench, Scutellaria galericulata L., Schizonepeta multifida (L.) Briq., and others].

In this city's flora, boreal genera Carex (4.1\%), Artemisia (2.2\%), and Potentilla (2.4\%) are in the lead. Members of Carex occur mainly in floodplain and swampy meadows in the valleys of the Abakan and Tasheba rivers and along drainage canals (C. acuta, C. cespitosa L., $C$. disticha Huds., $C$. Dichroa, and others) and occasionally are present in steppes $(C$. duriuscula, C. pediformis C.A. Mey., and C. sabulosa Turcz. ex Kunth). Species of the genera Potentilla and Artemisia are the most persistent in the city flora and do not give up their positions even under the influence of all the combined urban conditions. Members of Potentilla (P. bifurca L., P. multifida L., P. tanacetifolia Willd. ex Schltdl., P. argentea L., and others) occur in steppefied meadows and steppe areas and along roadsides. Species of the genus Artemisia grow in steppefied meadows, along roadsides, and on open steppe slopes (e.g., A. annua L., A. vulgaris L., A. frigida Willd., and A. absinthium L.).

One of the leading positions belongs to the genus Astragalus, which includes 8 species here $(1.7 \%)$ (A. adsurgens Pall., A. uliginosus L., A. danicus Retz., and others). The genus Poa is represented by 7 species (1.6\%): e.g., P. annua L., P. pratensis L., and P. transbaicalica Roshev.

Xerophytic genera Oxytropis (O. nuda Basil., O. intermedia Bunge, O. strobilacea Bunge, and others) and Allium (e.g., A. ramosum L., A. lineare L., and A. tenuissimum L.) are each represented by 6 species $(1.3 \%)$ and were found mostly in steppes.

Mesophytic genera Ranunculus ( $R$. propinquus, $R$. acris, $R$. repens L., $R$. monophyllus Ovcz., and others, 6 species in total; $1.3 \%$ ), Viola (e.g., V. hirta L., V. patrinii Ging., and $V$. arenaria DC.), and Veronica (V. krylovii Schischk., V. longifolia L., V. incana L., and others) are each represented by 5 species $(1.1 \%)$ and grow in meadows and parks.

Taxonomic analysis showed that the flora of higher vascular plants has formed from native species and introduced species.

Lichens in the city of Abakan are represented by 33 species affiliated with 18 genera and 8 families. The average number of species per family proved to be 4 .1. Two families that are above this average are leaders in the study area: Parmeliaceae (9 species, 27.3\%) and Physciaceae (5 species, 15.2\%). The Parmeliaceae family, with the top genus Parmelia, includes lichens that prefer a woody substrate and have a foliose thallus. Members of the Physciaceae family possess a foliose thallus and reside on rocks and trees. Quite often, members of these families were found on tree trunks in parks and alleys, for example, at the intersection of Marshal Zhukov Str. and Ozernaya Str. as well as in the central park. Among diverse farophytes, most of the species were found on trees Betula pendula Roth and $P$. sylvestris L.

Families Lecanoraceae, Candelariaceae, and Teloschistaceae each include 4 species here $(12.1 \%)$, which have a crustaceous thallus and reside on stony and woody substrates. 
Members of these families were most often noted in places containing a stony substrate, in the steppe areas of Mount Samokhval, and on various buildings and other human artefacts (e.g., concrete fences, corrugated asbestos boards, and fences).

Families Acarosporaceae and Hymeneliaceae feature 3 species $(9.1 \%)$ residing on a stony substrate and having a crustaceous thallus. Members of these families were found on concrete fences.

The average number of lichen species per genus turned out to be 1.83. Eight genera are above average in this regard and are represented by 23 species in total, which is $69.0 \%$ of all the lichen species in the city. The remaining 8 genera each have 1 species here, which is $31 \%$ of the total number of lichen species in Abakan.

The genus Lecanora, which includes 4 species here, contains lichen species with a crustaceous thallus. They prefer a stony substrate and, ecologically speaking, belong to xeromesophytes ( 2 species), cryophytes (1 species), and mesophytes ( 1 species). Members of the genus Acarospora (4 species) prefer a stony substrate, and their thallus is crustaceous. In terms of ecology, they are either xerophytes (3 species) or xeromesophytes ( 1 species). Taxa of the genus Parmelia (3 species) prefer an arboreal substrate, and their thallus is foliose. Ecologically, they are xerophytes (all 3 species). Members of the genus Aspicilia (3 species) prefer a stony substrate, and their thallus is crustaceous. Ecologically speaking, they can be categorized as xerophytes (1 species), mesophytes (1 species), and xeromesophytes (1 species). Members of the genus Xanthoria (2 species) prefer a stony substrate, and their thallus is either foliose $(2$ species $)$ or lobed (1 species). In terms of ecology, they are either xerophytes (2 species) or xeromesophytes (1 species). Taxa of the Physcia genus (2 species) prefer a woody substrate, and their thallus is foliose. Ecologically, they are xeromesophytes. Members of the genus Caloplaca (2 species) prefer a stony substrate and possess a crustaceous thallus. In terms of ecology, they are mesophytes.

Such family and genus profiles are characteristic of the steppe vegetation belt $[8,9]$.

Overall in this study, 125 species of basidial macromycetes were identified belonging to 75 genera, 34 families, 6 orders, and a single class, Agaricomycetes.

The entire Abakan mycobiota is affiliated with 6 orders: Agaricales (46 genera and 78 species), Russulales (3 genera and 11 species), Boletales (6 genera and 7 species), Hymenochaetales (3 genera and 6 species), Polyporales (16 genera and 21 species), and Gloeophyllales (genus 1 and 2 species).

The top orders-judging by the number of species - are Agaricales and Polyporales. The found Agaricales members are cosmopolitan. The agaric fungi in this city mainly are saprophytes on soil (Hu), on wood, and tree waste; there are also mycorrhiza-formers (Mr). This order here includes the agaric family, i.e., lamellar fungi (Agaricaceae), with the hymenophore in the form of plates (lamellar hymenophore), as well as boletus fungi (Boletaceae) with the hymenophore in the form of tubes (tubular hymenophore).

The order Polyporales takes the second place. The abundance of this order's species is predetermined by the presence of woody plants in the phytocenosis and by the stage of their vital power. Members of the order are typical xylotrophs (Lep) and (Lei) and are parasites (P) acting as decomposers in the biogeocenosis. Most species of the order Boletales are mycorrhiza-formers (Mr) and correspond to a very specific wood species.

The average number of fungal species per family is 3.8. There are 7 major families in Abakan: Agaricaceae, Strophariaceae, Polyporaceae, Marasmiaceae, Russulaceae, Coprinaceae, and Tricholomataceae. In the family profile, Agaricaceae (18 species $14.4 \%$ ), Polyporaceae (13 species 10.4\%), Strophariaceae (12 species, 9.6\%), and Russulaceae (10 species, $8.0 \%$ ) stand out. Members of the Russulaceae family engage in symbiosis with Populus laurifolia and P. sylvestris. 
The fungal genus profile is dominated by 10 genera in terms of the number of species found here. The other 65 genera are represented by less than 4 species. Major genera include Agaricus, Pholiota, and Lactarius, each having 6 species, which is $24.0 \%$ of all the fungal species found in Abakan in this study. Other major genera such as Trametes and Lycoperdon include 5 species or 13.0\%. Genera Lepiota, Amanita, Russula, and Phellinus each are represented by 4 species or $27.0 \%$. The genus Coprinus features 3 species here.

The leading role of the genus Pholiota is explained by the finding that areas with meadow and steppe vegetation are widespread in the city under study. In these habitats, the presence of well-developed humus layers of soil is typical here, which is considered one of the best conditions for the spread and growth of the trophic group; this group here includes the species of these genera, which are humus saprophytes.

Members of the genus Lactarius are confined to habitats close to a specific species of a woody plant because they are mycorrhiza-formers (Mr). The found individuals showed a specific association with tree species of genera Populus, Betula, and Pinus.

Overall, the taxonomic analysis suggests that the Abakan mycobiota is dominated by cosmopolitan taxa associated with urban environments.

In conclusion, it is worth mentioning that the species profile of higher vascular plants in the city of Abakan is characterized by rapid changes, which manifested themselves even in the study period (observations during 10 years). Consequently, further monitoring studies are necessary to clarify the stability of the ratios seen here in the flora taxonomy.

\section{References}

1. E. G. Lagunova, O. A. Vasileva, Problems of botany of south Siberia and Mongolia (2016)

2. N. G. Ilminskich, The florogenesis in urbanized environment Ekaterinburg (UrO RAN, 2014)

3. N. N. Tzvelev, The vascular plans of northwestem Russia (Leningrad, Pskov and Novgorod regions) (St.Peterburg, SPHFA, 2000)

4. A. N. Oxner, Handbook of the lichens of the U.S.S.R. Morphology, systematic and geographical distribution (Leningrad, Nauka, 1974)

5. E. S. Ankipovich, Catalog of flora of the Republic of Khakasia (Altay University Publishing House, Barnaul, 1999)

6. M. A. Berezutsky, Botanical journal 83(9) (1998)

7. A. V. Panin, M.A. Berezutsky, Botanical journal 92(8) (2007)

8. N. S. Golubkova, Analysis of the lichen flora of Mongolia (Leningrad, Nauka, 1983)

9. O. A. Zyryanova, Siberian ecological journal, 17(2) (2010) 